\title{
BRIDGING THE GAP BETWEEN THEORY AND PRACTICE IN LANGUAGE REVITALIZATION EFFORTS IN AFRICA
}

\author{
Olushola B. Are
}

\begin{abstract}
This paper examines the increasing concerns about language endangerment in SubSaharan Africa, and assesses the necessity and practicality of language revitalization efforts in some situations in the region in light of a number of practical problems of implementation. The paper identifies the need for a clearer paradigm of revitalization efforts, and recommends an approach that recognizes the hard reality that not all endangered languages can receive attention toward functional restoration due to the practical matters involved. The paper proposes archival preservation in such cases, while strongly supporting functional revitalization where the concerned languages a meet some suggested thresholds of viability.
\end{abstract}

Key Words: African languages, language revitalization, language endangerment, language death.

http://dx.doi.org/10.4314/gjl.v4i1.2

\section{Introduction}

Language is central and fundamental to communication, culture, and the very essence of people's collective identities. The permanent loss of any language is therefore a serious matter. A caption on the Web Site of the Hans Rausing Endangered Language Project, which describes language death, says quite succinctly, "...every last word means another lost world."

It is clear though that the dominant perspective among the experts is to view language shift as inimical to human society, and to suggest measures to revitalize the vulnerable or endangered ones. This is the perspective of Fishman (1999, 2007), Crystal (2000), Obiero (2010). Agitations by language rights advocate who take up the cases of "marginalized" minority languages have recently fueled the revitalization train (Are 2011). In the case of the latter, 'revitalize' often means the restoration of 
the use of such languages. The positions of the scholars cited above hinge on the belief that there is enormous good in preventing languages from dying. For example, Crystal (2000), lists and extensively discusses the socio-cultural, historical, scientific, and identity related values of preserving languages.

African languages tend to generally thrive better than languages of other continents (Blench 1998; Mous 2003). Yet, there are a number of instances of endangerment as will be presented in a subsequent part of this paper. In these cases, clear paradigms of response toward maintenance are needed. Reports of successful language maintenance and revitilisation efforts in Africa are paltry. In this regard, Obiero (2008) argues that while reports on language shift and death in Africa are rife, there are no clear-cut accounts of language revival projects. Indeed, he argues further that on a world wide scale, only Hebrew and some Hawaiian and Maori languages have really been brought back from the brink to become normal mediums of communication in speech communities. This suggests the need for more effective and realistic paradigms of revitalization efforts. This paper is intended to be contribution toward solving this. It proffers a solution that emphasizes the need to face the reality that language death is a natural element of the ecology of languages and in many instances may be extremely difficult if not impossible to reverse. In this wise, a system that helps to avoid wasting time and effort on trying to revive the use of doomed languages is proposed. This proposal favours the use of technology to archive such languages, while reserving real conservation for struggling languages that still have some reasonable chance of surviving. A method of determining the current condition of the concerned languages is also proposed.

\section{General perspectives on language shift, language endangerment and language maintenance}

Knooihuizen (2006) argues that language shift has been a research topic within linguistics for approximately half a century, but a clear and universal definition seems to be lacking. Two key issues however govern different definitions. The first issue is the fact that language shift involves changing patterns of language use. The second issue is that language shift happens in a situation of language contact. With these in mind, one can safely posit that language shift refers to a situation where a speech community gradually changes its pattern of language use, such that there is a gradual gravitation from the language of that community to another language with which it is in constant contact. This often leads to threats to the existence of the language being ignored. When a language in this situation begins to fall out of use, it can ultimately become endangered, and it may eventually die. To prevent this, linguists often prescribe measures to reverse the process of shift. Such measures amount to language maintenance or language revitalization. 
The rate at which languages of the world disappear is quite alarming. Several scholars are of the opinion that up to $90 \%$ of the world's languages may well be replaced by dominant languages by the end of the $21^{\text {st }}$ century, which would reduce the present number of almost 7,000 languages to less than 700 (Brenzinger and De Graaf 2005). This is the kind of grim prospect that troubles linguists, anthropologists and other interested scholars.

Fishman (1991) provides some foundational insights into the nature of this problem. Significantly, he explains the cultural loss associated with language death but expresses optimism about the possibility of shift reversal. He gives examples of successful attempts at language shift reversal, arguing forcefully against those who claim that attempts to reverse language shift are futile and unnecessary. Fishman also provides an intergenerational transmission theory, which provides a framework for understanding the status of languages in terms of how secure they are from shifts that can lead to endangerment.

In the same direction, Crystal (2000) also emphasizes the benefits of language shift reversal. He identifies the need for linguistic diversity, arguing that humanity should strive for linguistic and cultural diversity because such diversity is inherent in human nature. This, he points out, is as crucial as agitations for the preservation of biological species to keep eco-diversity. Crystal also stresses the need to recognize the value of language as a strong factor of collective identity, and the fact that the loss of identity which language death brings can be a problem for many people. In addition, he points out that language must be valued for its role as repository of historical and scientific knowledge. Crystal therefore expresses strong views in favour of maintenance and revival efforts for dying languages. These, according to him, would primarily involve getting all the relevant statistics about the languages in question and then implementing six steps, which include:

- Increasing the prestige of the threatened/ endangered language among its speakers

- Economically empowering the speakers relative to the dominant groups

- Politically empowering the speakers

- Giving the language a presence in education

- Putting the language into writing (if this is not yet done ), and

- Using electronic technology as may be required to document

These steps, according to Crystal, are based on observations of interventions in different parts of the world towards reversing language shift. This approach is significant as it involves a practice-based blue print for intervention.

Adegbija (2001) identifies a number of practical intervention measures, which include the need to fashion out an articulated philosophy of Reversing Language Shift (RLS). He also raises the need for the affected communities themselves to be involved 
in revitalization efforts, and the need for governments to institutionalize multilingualism as a policy. This must go beyond the tendency to recognize (officially) major languages at the expense of the smaller ones. This, according to Adegbija (2001) is crucial because one of the major factors responsible for language shift in Africa is the "inferiority syndrome" created by the dominant and prestigious position of not only the European languages but also the recognized local major languages.

The increase in interest in this issue has been phenomenal since the publication of Fishman's work in 1991. The sub discipline called RLS has had an impact worldwide, particularly at the level of the United Nations (UN) where several declarations and initiatives have been made. These include:

- the Declaration of Vienna of the World Conference on Human Rights (1993), affirming the right for "persons belonging to minorities to use their own language."

- the call of the General Assembly of the United Nations for more attention to multilingualism (December 1999);

- resolution 56/262 (Part II) of the General Assembly of the United Nations focusing on the preservation and protection of all languages; and

- the report of the Secretary-General of the United Nations at its fifty-eighth session (2003), on measures to protect, promote and preserve all languages.

The specific UN organ involved in direct effort regarding the above is UNESCO, and it has come up with a number of policy guidelines that have formed the bases of concerted international efforts to reverse the trend of language deaths. These include the Universal Declaration on Cultural Diversity, Convention for the Safeguarding of the Intangible Cultural Heritage and the Recommendation on the Promotion and Use of Multilingualism and Universal Access to Cyberspace. The Universal Declaration on Cultural Diversity (for example) aims at:

- sustaining linguistic diversity and giving support to expression, creation and dissemination in the greatest possible number of languages;

- encouraging linguistic diversity at all levels of education, and fostering the learning of several languages from the youngest age;

- incorporating traditional pedagogies into the education process with a view to preserving and making full use of culturally appropriate methods of communication and transmission of knowledge; and

- encouraging universal access to information in the public domain through the global network, including the promotion of linguistic diversity in cyberspace. 
The works of the scholars cited above (as well as the UN efforts) are based on the notions that humanity developed and needs diversity, and that language reflects past experience and is a tool for socializing and for expressing and transmitting social and cultural practices. They also involve the belief that language contributes to human knowledge and is an amazingly rich and diverse product of the creativity, which serves as a strong factor of identity. The need for maintenance or revitalization is therefore largely considered by most stakeholders to be pertinent.

\section{Language endangerment in Sub-Saharan Africa}

Although the phenomenon of language endangerment exists all over the world, it is believed that in percentage terms, the rate of language endangerment and extinction in Africa is less than what obtains in other parts of the world (Blench 1998; Mous 2003). This is quite ironic because Africa is more linguistically diverse than any other continent. In addition to this, the linguistic dynamism in Africa is such that new linguistic systems continue to evolve to enhance the peoples' ability to negotiate through the social complexities engendered by multilingualism. Kiessling and Mous (2014) document the case of some urban "youth languages" in different parts of Africa. Though the categorization of these emergent systems as languages and not mere pidgins-in-progress is somewhat problematic, their emergence further reflects the unique dynamism of the African situation.

Yet, the need for one form of intervention or the other in language shift still exists in some parts of Africa. The continent has big languages and small languages, with the big languages often serving as lingua francas to aid communication between peoples whose languages are mutually unintelligible. This situation has historically placed the smaller languages under pressure as society becomes more modern and interconnected, such that the dominant languages that serve as bridge builders tend to become dominant at the expense of the smaller ones (Blench 1998).

In recent times, human society has tended to favour languages that enhance people's economic, social and political connections to the wider society. Are (2011: 11) argues that:

Traditionally and historically, languages have emerged and survived to serve the primary role conveying the thoughts, ideas, concepts and world view of peoples in such a way that internal connections are guaranteed. Today, however, it appears as if closer contacts between peoples have engendered a situation in which the communicative value of a language is becoming more and more a function of how the language is able to help people to connect to a wider world. Globalization involves reaching out, and only languages that reach out may 
survive. Those that cannot reach out will contract, become moribund, and eventually become history.

The above comments depict a crucial reality in language ecology which society needs to come to terms with where necessary.

The challenge in this regard will get more urgent as the nations of Africa develop. Amano et al. (2014) in a new study, empirically prove that there is a clear relationship between the per capita GDP of nations and the extent of language extinction. The higher a society's GDP, the higher the rate of extinction. This is because higher GDP and the attendant developmental advancement enhance many of the social processes that precipitate language extinction. Such social processes include the crucial factor of urbanization, which moves people to areas of population concentration where they naturally opt for the dominant languages that will enhance their social and economic integration and empowerment. Ironically, development, which Africa needs so desperately, is a potent threat to her cherished linguistic diversity.

The rates of endangerment vary in different parts of Sub-Saharan Africa. Figures obtained from the eighteenth edition of Ethnologue are presented in the table below. The table reveals the number of languages that have institutional support, the number that are developing and the ones that are vigorous. It also reveals the number of languages that are in trouble and the number that are out rightly dying.

Table 1: Language virility and endangerment in Sub- Saharan Africa

\begin{tabular}{|l|l|l|l|l|}
\hline & West Africa & Central Africa & East Africa & Southern Africa \\
\hline Institutional & 58 & 32 & 83 & 14 \\
\hline Developing & 221 & 157 & 136 & 6 \\
\hline Vigorous & 501 & 350 & 139 & 19 \\
\hline In Trouble & 57 & 96 & 53 & 3 \\
\hline Dying & 49 & 41 & 21 & 6 \\
\hline
\end{tabular}

The figures above reveal that while most languages in Sub-Saharan Africa are still quite stable, a number of languages are in trouble or dying. It must be pointed out though that it is not a simple cut and dried matter to determine that a language is in trouble or at risk of dying. There are different stages and processes a language can be going through for it to be so classified. This of course informs Fishman's Graded Inter-generational Disruption Scale, which identifies eight stages in the process of language loss. This is explained later in this paper. 
The prospects for endangered Sub-Saharan languages are getting dimmer because most of the factors associated with their recession continue to play out in their sociolinguistic context. In the specific case of languages in the Middle Belt area of Nigeria, Blench (1998) identifies a number of factors of language disappearance that continue to affect small languages. These include: assimilation to larger and more powerful surrounding languages, assimilation to smaller but culturally more powerful languages, assimilation to English and demographic crises caused by labour migration/ urbanism. Mous (2003) identifies similar reasons for language loss on the entire continent. He adds that the demise of traditional economies, central to the identities of groups, has also led to shifts to dominant languages.

A 2003 report submitted to the South African Ministry of Education by a ministerial committee on the development of Africa languages as medium of instruction in higher education makes an interesting general observation. It states that "preference for English instead of African languages in all formal sectors of society both private and public continues unabated in general social practice" (p.4). This situation is described in the report as a crisis situation when viewed within the context of attempts at the preservation and maintenance of African languages. Largely, the endangerment of African languages is a direct consequence of language shift.

Different efforts are being made to improve the fortunes of endangered languages. Quite recently, for example, the West African Linguistics Society in conjunction with the Linguistics Association of Nigeria organized a conference on this matter. The conference was themed "Research, Documentation and Sustainability in the Development of West African Languages." The conference explored how language documentation can advance the course of bringing attention to the very important aspects of description, development, modernization and integration of local (West African) languages with global information infrastructure. It is in view of the current push that this paper is pertinent at this time.

\section{Problems with theory, policy and implementation in Sub-Saharan Africa}

There are many ideas about language revitalization out there (as exemplified by Fishman 1991, Adegbija 2001, Crystal 2010). Yet, it is important to note the fact that there remains a need to fine-tune some grey areas of implementation in Africa.

A crucial factor in this regard is the matter of establishing the clear need, if any, for any form of intervention. This issue must not be taken for granted. 'Smallness' in terms of number of speakers is not an absolute factor of endangerment. Languages with as few as 500 speakers are known to be surviving quite well (Austin 2006: 4). There is a need to go beyond raising alarm on the basis of mere conjecture. Scientific studies with hard data are required in order to determine the true state of languages. Yet, there is a paucity of this kind of study. 
In addition to this, there are some other foundational issues, which are yet to be sorted out in many instances. For example, African linguistics is still bedeviled by the problem of ascertaining the criteria for determining which linguistic systems are languages on their own and which ones are dialectal variations of other languages (Blench 2013). Blench points out that there are as yet no foolproof scientific ways of carrying out the absolute categorisation. The criteria of mutual intelligibility, lexicostatistic count and sociolinguistic factors remain problematic. Accordingly, Blench concludes that the only feasible option is to base classification on the judgments of individual linguists and the views of the speech communities, though such may not conform to any unitary standards. The summary of this is that we are yet to ascertain clearly the identity of many of the languages in question, and how they are used in the different interacting communities where they are found. This is hardly the ideal situation for revitalization efforts.

Another practical hindrance is the matter of the financial implications of maintenance, especially in societies where there are more pressing basic survival issues. Prioritizing language issues can be problematic in these places. Crystal (2000) describes arguments in this regard as "spurious" on the basis that language is a human asset, which from the perspective of the human capital theory, must be preserved even where the benefits are not really quite tangible or concrete.

The big question is: can this kind of "human capital" view be pursed in conditions where the choices are between expending resources on thing that are not so tangible, and expending them on basic issues of hunger, shelter, basic education and infectious diseases? The reality is that in Africa, some of the views that linguists relentlessly express will remain practically problematic for politicians and administrators who draw societies' scales of preferences, as well as for NGOs.

One instance (albeit extreme) that can illustrate these difficulties very clearly is the case of Adamawa State in Nigeria. The state has at least 58 languages, most of which are not on a sound footing in terms of long term viability. They are under severe pressure due to the dominance of Hausa and Fulfulde in the state (Seibert 2013). The threats to these languages increase as more and more people learn to use English via western education. Is it realistic for a state with a poverty-stricken citizenry and an average annual budget of less than $\$ 580$ million to plough resources into conservation of over 50 struggling languages, while its citizens endure the pangs of hunger? Assuming Nigerian politicians really want to help the people, it is doubtful whether they would feature language revitalization on their list of priorities in the near future. It would simply be immoral for them to do so! Obviously, the same could apply to many governments in Sub-Saharan Africa. 
Fishman (1991) recognizes the difficulties in this kind of situation. He observes that questions can be raised about the wisdom of expending much on language preservation, pointing out that:

When some nations at still at each other's throats while others are belatedly preoccupied with headaches of working out their own approaches to pluralism in government and in production, when cities the world over are crumbling due to crime and industrial pollution, when drugs are decimating the young, when poverty and incurable illness are ravaging millions throughout the world... is this the time to worry about, much less try to do anything on behalf of threatened languages... whose history and majority of their own former speakers have (apparently) confined to the dustbin of history (p.2).

Apart from the matter of financial priorities, it is important to recognize the intense politics involved in language management issues. Languages are often tied to strong ethnic sentiments that politicians are understandably reluctant to offend. Often, African governments who more often than not struggle with seething ethnic tensions, see the language issue as a sleeping dog that is better left to lie. Adedimeji (n.d) explores this reality, using the Nigerian situation as a microcosm. He points out as illustration the deep disaffections generated by the mere constitutional recognition of three major Nigerian languages to the exclusion of the hundreds of small languages. Even where the threats of social disharmony may not be very palpable, the issue of resources will still show up. Plowing resources into the study and maintenance of languages, which sometimes have less than 500 speakers, is always going to be problematic for people in charge of these nations' resources.

As painful as this may sound to linguists and some other concerned advocates of language conservation, it may never be possible (from the economies of scale perspective) to devote enough time and resources to the required work needed if all endangered languages are to be preserved. It is therefore imperative to clearly understand the kind of preservation works that are possible or feasible for different languages. In other words, the preservation objectives must be understood. It is suggested here that there are two possible choices of objectives from which to choose.

The first objective may be to aim at ensuring the survival of languages as continuing means of communication in a speech community. This can be referred to as functional preservation. This is the objective that would involve such language enhancement strategies as role allocation to threatened or endangered languages and the attendant language material development. For example, role allocation helps to entrench the use of a language by 'forcing' the relevant community to use it more and more. 
The other choice of maintenance objective can be called archival preservation. This objective does not involve any attempt to retain the language as a living system of human communication. It involves simply keeping the knowledge of the languages for posterity. This perhaps is the kind of practice which Dauenhauer and Dauenhauer (1998), cited in Walsh (2010), condemned as a technical fix which actually impedes "genuine training and interaction." The hard truth is that for many struggling languages, this is the only alternative to complete extinction.

The archived language can still be immensely useful to humanity. For example, some historical knowledge has emerged from the study of ancient languages via their writing systems, despite the fact that such languages or writing systems are no longer in use. It is important to lay strong emphasis on the place of archival preservation because some scholars often discuss reversal of language shift as if it is possible to keep all languages going in their various speech communities. This is pure fantasy. Fishman (2001) acknowledged that a return to the "golden past" should not be the aim of attempts to reverse language shift. He argues rather that it is about achieving "greater self regulation over the process of socio-cultural change which globalization fosters" (Fishman 2001: 6). Actually, the truth needs to be put more bluntly. Many languages appear to have really gone over the edge and beyond redemption for dayto-day use. Roger Blench in his website does this quite succinctly. He opines that "...there are a large number of genuinely endangered languages, many of which are moribund. Spoken only by a small number of old people, often with few teeth and wayward enunciation, recovering their language is often difficult. These languages are not going to be revived..." Frankly, languages like these may only be redeemable purely for archival purposes.

Making this distinction between functional preservation and archival preservation is the key to sorting out the confusion of impracticality that characterizes many good intentioned and lofty proposals regarding language maintenance. When this background principle is perfectly understood, a number of criteria can be drawn up and used to rate threatened languages, such that a dispassionate decision can be made to determine the kind of preservation effort suitable to them.

This would involve understanding the fact that the matter of endangerment is not an absolute concept. It is more of a process, such that what is to be done about a language would depend on the stage it is at in the long process between being virile on one side of the continuum and being moribund on the other side. Fishman (1991) suggested a Graded Intergenerational Disruption Scale as a standard to assess the extent of endangerment. Other scholars have severally revised this eight-stage scale. The merits or otherwise of these scales should not be an issue. The important thing is to identify some criteria to place languages' level of virility or otherwise as a prelude to making decisions on the kind of intervention to pursue. 
Such criteria could include the following:

- Level of intergenerational language transmission. This involves the extent to which a language is being transmitted from one generation to the next. This is indeed the most commonly used factor in evaluating the vitality of a language.

- Absolute number of speakers. Although some tiny language groups have been known to survive for long periods, the general trend is that very small ethnolinguistic groups are more prone to disappearance in the face of migration due to economic factors, warfare, or natural disaster than larger ones. Such languages may also easily merge with larger neighboring ones. Languages may be rated in accordance with this factor.

- Proportion of speakers within the total population. The number of speakers of the ancestral language in relation to the total population of an ethno-linguistic group is a significant indicator of language vitality.

- Nature of shifts in domains of language use. The survival chance of a language is also, to some extent, a function of how and where the language is used in different spheres of society. The more it is used in different spheres, the better its chances of survival.

These criteria can be easily measured via statistical tools. For example, a rating scale can be created to score the status of the languages in question on the set criteria. The first benefit of a process like this will obviously be a clearer picture of the true state of the languages involved, freeing the attendant decisions from the menace of being conjecture based. More significantly, decisions can then be made to the effect that the most viable languages can be chosen for functional preservation while the 'poor performing' ones may receive archival preservation efforts.

It must be said, though, that the financial and logistic requirements of archival preservation are huge and may overwhelm governments, researchers or NGOs in any African country. It is suggested here that having established which languages are suitable for archival preservation, a scale of preference may be drawn up in such a way that the most at-risk ones are addressed first, to ensure that essential data are collected while the opportunity exists.

With regard to functional preservation for the most viable languages, the questions may be asked: is it not wiser and more urgent to try to help the most vulnerable in a list of endangered languages? It may be argued that the sickest and most at risk patients often receive the most urgent and most intensive care in the hospital. Indeed, doctors are sometimes pulled away from less endangered patients to manage emergency cases.

This researcher posits that the management of threatened and endangered languages should be handled the other way round. The suggestion being proposed here is best 
illustrated by the situation of a farmer whose poultry are sick with a life threatening infection. Assuming he has a thousand birds sick but only has the drugs to treat five hundred, he would have to decide which five hundred to treat. Obviously, it would not be wise for him to start with the ones that are almost dead, as they may not make it anyway. In that case he would have no drugs left to treat the healthier ones. The conditions of the healthier ones would subsequently deteriorate and they would die too. It would be more reasonable for him to start his treatment with the birds with better chances of survival, and ignore the birds that are already half dead. This is the logic of the selection recommended here. Indeed, the fate of the struggling languages is to some extent a function of a natural process of linguistic selection similar to Darwin's theory of natural selection. Human intervention must be measured dispassionately, especially where resources are scarce, to avoid unnecessary waste.

In summary, it is proposed that where it seems most certain that a language is doomed (having empirically calculated its situation in accordance with the proposed system) no effort of functional preservation should be attempted. Archiving would be a better option.

\section{Archival preservation}

Preserving the knowledge of the structure, the folklore, science and attendant historical and cultural treasures of a language has become much easier today than it was several years ago. This is a result of the explosion in computer technology and its possible applications to language. There are several areas in which computer technology can be deployed to preserve a language. Some of them are mentioned and discussed below.

\subsection{Documentation}

Language documentation is one of the key issues in any attempt to preserve a language. It involves assembling a comprehensive record of the elements, characteristics and systems of a language such that there can be standard, credible and citable sources of data on the language. Modern advances in computer technology have made available means of documenting endangered languages fast and efficiently (Russell 1992). In modern times the chief method of studying the system of a language is corpus linguistics, which largely depends on the use of computer programs. Today, there are electronically readable corpora, making it possible to do in seconds the kind of linguistic analysis that would normally take months. Today, it is possible to use computers to generate the corpora of languages and preserve them for posterity. Hundreds of years down the line when such languages may have disappeared as normal means of day to day conversation, their systems can still be understood and subjected to detailed study where the need arises. 
A number of benefits arise from this. Computer based programs are now used to write in previously non-written languages, produce dictionaries, and compile digital and hard copy folk literature and history which can remain accessible for ages. Russell (1992) refers to a situation where within two weeks of exposure to computer language tools, five Kom speakers in Cameroon produced a 2,000 word dictionary from a 25,000 word body of literature they wrote in those two weeks.

This is an illustration of the kind of contribution that computer technology has made to language documentation and by extension, archival preservation. As earlier said, even when such languages are long gone from the real world, they can still be with us in the virtual world. People who do not speak those languages would still be able to enjoy their literature and knowledge, still using computers. This bring us to the crucial issue of machine translation.

\subsection{Machine translation}

The availability of computer based machine translation technology presents the possibility that a language that ceases to exist as the communication tool of any community could still be understood many years down the line. Of course, that is if the engineering and computational challenges of integrating such languages into translation software are overcome while the languages are still being used by some people. This brings to mind the urgency of focusing on the digital capture of the systems of all natural languages while this may be done. Odejobi and Adegbola (2010) highlight the enormity of the challenge in view of the complexity associated with translating one language to another and the difficult task of computationally encoding "the processes underlying the expertise of a human translator." (Odejobi and Adegbola 2010: 878)

These difficulties would only require more urgent efforts. Obviously, the very fact that computer based machine translation is today an integral part of computer mediated communication gives room for optimism. The imperfect nature of these systems is all too obvious, but they provide the best opportunity to make it possible for future generations to experience (in their own languages) texts of languages that are no longer spoken. Indeed, it would even be possible to hear close semblances of what these languages sounded like when they were spoken. This would be available via digital recordings and text to speech technology.

\subsection{Text to speech}

Text to speech is an aspect of speech synthesis, which involves the conversion of letters to sound or speech form. These systems are language specific and must be developed for each language. The beauty of it in the context of archival preservation is that where it exists, it can be used to convert written text of language into the sound 
equivalents many years after the disappearance of the speech community. Future generations can locate written texts and hear what they sound like. This is a developing technology. Today, the sound outputs of text to speech facilities often sound unnatural, lacking some of the essential supra-segmental features of speech. However, they continue to get better.

This technology, like the previously mentioned ones, is only applicable to language conservation in a context where the attendant challenges have been addressed. These challenges include computational challenges, engineering challenges, and human resources challenges (Odejobi \& Adegbola 2010).

\section{Concluding Remarks}

Linguistics is awash with studies of threatened and endangered languages, and in recent times, there appears to be a sense of urgency characterizing the discussions. The overriding consensus that languages need to be preserved is lofty and credible. Yet, there is a need to remind African scholars of some practical consideration that need to go into preservation efforts in order to bridge the gap between theory and policy on one side, and practical implementation on the other side.

While the practical problems identified in this paper cannot be eliminated from any language development program in Sub-Saharan Africa, a lot of progress can be achieved if the countries concerned can articulate clear-cut criteria for preservation efforts, thereby making the decision processes less political, and the implementation process more realistic and achievable. It is in this light that the approach explained in this article is advocated.

In order to fine tune a discussion of these issues, this paper earlier identified a number of questions to be addressed, which relate to the necessity or otherwise of language maintenance and revitalization, their practicality, as well as the question of the type of maintenance and revitalization that would be suitable. Obviously, efforts remain vital in cases where endangerment is clearly and scientifically established and not where it is merely assumed. However, revitalization in the sense of restoring the speech community is not always feasible. Therefore functional or archival preservation should be deployed as appropriate.

One must add, though, that the basic issue of identifying dying languages remains problematic in many instances in Sub-Saharan Africa. Indeed, there are still situations where scholars argue vehemently over the very existence of some languages as well as their true states. This situation can no doubt hamper any attempt to intervene meaningfully. More studies are needed in order to unravel some of the abiding mysteries regarding many language situations especially in complex situations like the Mambila Plateau area (Connell 1997). Concerted efforts must be made to come up with uniform standards for identifying languages and distinguishing dialects, such that 
individual discretion and language speakers' views would not be the determining factors.

Many aspects of language preservation work may not necessarily involve governments directly. Much important language research work has been done and is being done simply via post graduate work in universities, and via funding by nongovernmental organizations as well as wealthy members of the affected speech communities. This is crucial as a way of freeing governments from the decision challenges that often arise. Such options must continue to be pursued vigorously.

\section{References}

Adedeji, Mahfouz A. n.d. The unifying role of English in a multilingual nation: the case of Nigeria.

Available from:

https://www.unilorin.edu.ng/publications/ADEDIMEJI/THE\%20UNIFYING\%20ROLE\%2 0OF\%20ENGLISH\%20IN\%20A\%20MULTILINGUAL\%20NATION.htm. (accessed June 2015)

Adegbija, Efurosibina, 2001. Saving threatened languages in Africa: A case study of Oko. In Joshua Fishman, ed., Can Threatened Languages be Saved? Reversing Language Shift Revisited pp. 284-308. Clevedon: Multilingual Matters.

Are, Olushola, 2011. Toward a practical approach to the challenges of multilingualism in Africa. California Linguistics Notes, 34.1.

Available from: http://english.fullerton.edu/publications/cln/clnarchives/2011winter/Aremultilingualism.pdf (accessed 28 March 2014).

Amano, Tatsuya et al., 2014. Global distribution and drivers of language extinction risk. Available from: http://rspb.royalsocietypublishing.org/content/281/1793/20141574.full.pdf (accessed $10^{\text {th }}$ Oct., 2014)

Austin, K. Peter, 2006. Survival of languages. Lecture delivered at the $21^{\text {st }}$ Annual Darwin College lecture series. Cambridge. Available from: http://www.mercatorresearch.eu/...files/...languages/Article\%20EOLSS.doc (accessed 22 June 2014).

Blench, Roger, n.d. Endangered languages documentation. Available from: http://www.rogerblench.info/Language/EL/ELOP.htm (accessed 20 May 2015). , 2013. An Atlas of Nigerian Languages.

Available from: http://www.rogerblench.info/RBOP (accessed $21^{\text {st }}$ June 2014). 1998. The status of the languages of Central Nigeria. In M. Brenzinger, ed., Endangered Languages in Africa pp. 187-206. Köln: Köppe Verlag. 
Brenzinger, Matthias. 2007. Language endangerment in Southern and Eastern Africa. In Matthias Brenzinger, ed., Language Diversity Endangered pp. 179-203. Berlin: Mouton De Gruyter.

Connell, Bruce. 1997. Moribund languages of Nigeria Cameroun Border Land. Paper presented at the symposium on language endangerment in Africa, Liepzig. July 29-31, 1997.

De Graaf, Tjeerd and Matthias Brenzinger, 2005. Language endangerment, documentation, preservation and maintenance. Contribution to the UNESCO encyclopedia of life support systems. Available from:

www.merctor-esearch.eu/.../endangered_languages/Article\%20EOLSS. (accessed 9 March, 2014)

Crystal, David, 2002. Language Death. Cambridge: Cambridge University Press. Press. 1997. The Cambridge Encyclopedia of Language. Cambridge: Cambridge University

Fishman, Joshua, 1991. Reversing Language Shift: Theoretical and Empirical Foundations. Clevedon: Multilingual Matters.

Fishman, Joshua, 2001 Why is it so hard to save a threatened language? In Joshua Fishman, ed., Can Threatened Languages Saved? Reversing Language Shift Revisited pp. 122.Clevedon: Multilingual Matters.

Kiessling, Roland and Maarten Mous, 2004. Urban youth languages in Africa. Anthropological Linguistics 46.3: 303-341.

Lewis, M. Paul, Gary F. Simons and Charles D. Fennig, eds., 2015. Ethnologue: Languages of the World. Eighteenth edition. Dallas, Texas: SIL International. Online version, available from: http://www.ethnologue.com (accessed 5 July 2015).

Ministry of Education, South Africa, 2003. The Development of indigenous languages as mediums of instruction in higher education. Report compiled by the Ministerial Committee appointed by the Ministry of Education, South Africa (2003).

Mous, Maarten, 2003. Loss of linguistic diversity in Africa. In Mark Janse and Sijmen Tol, eds., Language Death and Language Maintenance: Theoretical, Practical and Descriptive Approaches pp. 157-170. Amsterdam: John Benjamins.

Obiero, O. John, 2010. From assessing language endangerment or vitality to creating and evaluating language revitalization programmes. Nordic Journal of African Studies 19.4: 201-226 Available from: http://www.njas.helsinki.fi/pdf-files/vol19num4/obiero.pdf (accessed 19 June 2014).

2008. Evaluating language revitalization in Kenya: the contradictory face and place of the local community factor. Nordic Journal of African Studies 17.4: 247-268. Available from: http://www.njas.helsinki.fi/pdf-files/vol17num4/obiero.pdf (accessed 19 June 2014). 
Odejobi, Tunji and Tunde Adegbola, 2010. Engineering and computational issues in human computer interaction systems for supporting communication in African languages. In Rotimi Taiwo, ed., Handbook of Research in Discourse Behavior and Digital Communication: Language Structures and Social Interaction pp. 876-889. Hershey, PA: IGI Global.

Remco, Knooihuizen, 2006. Language shift, ethnolinguistic vitality and historical sociolinguistics: testing the models.

Available from: http://www.lel.ed.ac.uk/ pgc/archive/2006/2006knooihuizen.pdf (accessed 26 May, 2013).

Russell, Bernard H., 1992. Preserving language diversity: computers can be a tool for making the survival of languages possible. Cultural Survival Quarterly. Available from: http://www.culturalsurvival.org/publications/cultural-survival-quarterly/mexico/preservinglanguage-diversity-computers-can-be-tool- (accessed 14 January 2014).

Seibert, Uwe, 2013. Languages of Adamawa State. Available from: http://archive.is/ocKMm (accessed 14 January 2014)

Skutnabb-Kangas, Tove, 2000. Linguistic Genocide in Education or Worldwide Diversity and Human Rights. New Jersey: Lawrence Erlbaum.

The Hans Rausing Endangered Languages Project. http://www.hrelp.org (accessed 20 February 2014)

UNESCO Activities for Safeguarding Endangered Languages. Available from: http://lingsib.iea.ras.ru/en/articles/smeets.shtml (accessed 20 February 2014)

Walsh, Michael, 2010. Why language revitalisation sometimes works. In John Hobson, Kevin Lowe, Susan Poetsch and Michael Walsh eds., Re-awakening Languages: Theory and Practice in the Revitalisation of Australia's Indigenous Languages pp. 22-36. Sydney: Sydney University Press. 